\title{
SUPPORTING TRANSFORMATION
}

$\mathrm{T}$ his is the first of two volumes of proceedings of "Using Models and Simulations in Support Of Force Transformation" (UMSSOFT) - a three-day international conference, hosted by Bulgaria's Ministry of Defence at the "G.S. Rakovski" Defence and Staff College in Sofia, ${ }^{1}$ 26-29 June 2007.

Primary objective of UMSSOFT 2007 was to provide opportunities for decision makers, representatives of governmental agencies, and scientists to share experience from the implementation of methods, tools and latest research results in support of force planning and management, operations planning, and training in the new security environment, as well as to promote the implementation of objective, rational decision-making frameworks and management mechanisms. The conference allowed for identification of some key implementation challenges and priority research areas in support of the transformation of armed forces, as well as other security organizations. It also contributed to the development of a common knowledge infrastructure of concepts, methodologies, methods, and tools in support of transformation.

The conference was organized in two plenary sessions and two parallel tracks - one dedicated to decision support to operations planning, crisis management and training in a multinational, interagency setting, and the other - on decision support to defence and force planning and acquisition management.

This volume features selected papers from the first track, while the next volume of I\&S will reflect on the plenary presentations, summarizing major findings and recommendations, and will include the papers from the second track.

The overarching theme of this volume is the use of models and simulations in support of transforming forces and security sector organizations. It starts with a key presentation of a senior representative of the J7 Department of the General Staff of the Bulgarian Armed Forces. In his paper, Colonel Nikolov presents the approach of the

\footnotetext{
${ }^{1}$ For information about the college see http://rdsc.md.government.bg/EN/About/Akademi/ welk.php.
} 
Bulgarian military leadership, achievements and challenges in implementing CAX for effective and efficient joint training.

The rest of the contributions are split in two groups. The first group of papers is more of a theoretical and conceptual nature. Experienced researchers from Germany, Bulgaria and Ukraine discuss novel methods in modelling social systems, methodologies and advanced modelling techniques, as well as modelling frameworks.

The second group presents practical solutions and examples of successful implementation of advanced modelling approaches and techniques in analyzing, understanding, preparing for and responding to complex events and phenomena.

Unlike a regular volume of I\&S, this one does not contain a "monitor" section. As a compensation, the next volume will include comprehensive list of resources on transformation, covering thoroughly the developments in the area of modelling and simulation. 